\title{
3 Research Square

\section{Surgical Treatment for Avulsion Fractures of the Anterolateral Ligament Associated with Periarticular Fractures of the Knee}

\section{Xuelei Wei}

Tianjin Hospital https://orcid.org/0000-0002-6272-232X

\section{Zengliang Wang}

Tianjin Hospital

Yandong Lu

Tianjin Hospital

Jie Sun ( $\nabla$ xlwei66@sina.com )

Tianjin hospital

John Riehl

Pikeville Medical Center

Research article

Keywords: anterolateral ligament; periarticular knee fractures; avulsion

Posted Date: May 8th, 2020

DOI: https://doi.org/10.21203/rs.3.rs-26495/v1

License: (c) (1) This work is licensed under a Creative Commons Attribution 4.0 International License. Read Full License 


\section{Abstract}

Background: To confirm the existence of the ALL and evaluate the clinical outcomes of surgical management for avulsion fractures involving its insertion when associated with periarticular knee fractures.

Methods: Twenty-three patients ( 16 males and 7 females) with avulsion fractures of the ALL associated with periarticular knee fractures were fixed with a spider plate, cannulated screw, or suture anchor. Eight patients were diagnosed with distal femoral fracture, 10 with tibial plateau fracture, and 5 with tibial eminence avulsion fracture. All patients underwent X-rays at follow-up. Clinical and functional outcomes were assessed with the pivot-shift test, objective and subjective International Knee Documentation Committee (IKDC) score, Lysholm score, and Tegner activity scale.

Results: The ALL was found and identified as a distinct ligamentous structure in all patients. Pre-Segond repair, patients had significantly more instability as determined by pivot-shift test than seen postoperatively $(P<.0001)$. At final follow-up, the mean subjective IKDC score was $83.2 \pm 10.3$. Fourteen patients were graded $A, 6$ were graded $B$, and 3 was graded $C$ on the IKDC objective score. The mean Lysholm score was $85.4 \pm 12.2$. The mean Tegner score was $7.5 \pm 1.2$.

Conclusion: This study confirmed that the ALL is a distinct structure in the anterolateral portion of the knee. The fixation for the avulsion fracture of the ALL associated with periarticular knee fractures can be an effective procedure without specific complications. Longer term and comparative follow-up studies are necessary to confirm the effects.

\section{Background}

In 1879, Paul Segond first described the existence of a "pearly, resistant, fibrous band" at the anterolateral aspect of the human knee attached to an eponymous Segond fracture [5,30]. However, this band was not routinely discussed, identified, and confirmed during the subsequent century. In 2013, Claes et al. [5] reported on the anterolateral ligament (ALL) as a distinct and consistent ligamentous structure of the knee. Since then, investigation of the ALL grew and clinical interest into this structure developed. At present, many researchers advocate for this ligament's existence and have conducted morphometric studies $[2,5,10,12,13,16,17,36,38]$. However, some researchers have doubted the existence of the ALL, and corresponding studies have been unable to find a distinct ligamentous structure that stands out in the anterolateral part of the knee $[3,14,22]$. Additionally, there have been differing accounts of the ALL's anatomy in fetal knees. Helito et al. [19] reported that the ALL was present in all dissected fetal knees, while Sabzevari et al. [39] claimed that they could not prove the presence of a distinct ligamentous structure in the anterolateral complex area.

With the re-discovery and definition of the ALL, Claes et al. [6] confirmed that the Segond fracture is actually a bony avulsion of the ALL. Subsequently, Porrino et al. [35] identified the ALL on MRI and reported that the ALL was attached to the Segond fracture fragment. However, Shaikh et al. [41] reported 
an interesting conundrum: the Segond fracture occurs at the location of the tibial insertion of the ALL, as reported in the literature, while MRI was unable to identify any distinct ligamentous attachment.

Despite ongoing controversy in the literature, multiple biomechanical studies have demonstrated that the ALL plays a role in anterolateral rotatory instability related to the pivot-shift phenomenon $[24,26,32,33$, $37,40,44,45,47,49]$. Segond fractures are sometimes seen in periarticular knee fractures. However, specific fixation of the Segond fracture fragment is rarely given much consideration while the major fracture fragments are reconstructed and the treatment of the ALL avulsion fracture is often neglected. Therefore, the purpose of the current study was to determine the existence of the ALL in periarticular knee fractures seen with associated Segond fractures and report outcomes after treatment of the Segond fracture.

\section{Patients And Methods}

\section{Patients}

A total of 23 patients ( 16 men and 7 women) aged 23 to 55 years (mean: $40.7 \pm 9.1$ ) underwent open reduction and internal fixation for avulsion fractures of the ALL associated with periarticular knee fractures from June 2014 to May 2017. The inclusion criteria for this study were (1) periarticular fractures of the knee, including distal femoral and proximal tibial fractures, (2) absence of injury to nerves, blood vessels, and major organs, (3) a follow-up period of $\geq 2$ years, (4) the ability to walk normally using the ipsilateral knee joint before injury, and (5) no obvious osteoarthritis or any history of trauma. The exclusion criteria were (1) a simple Segond fracture, (2) concurrent injury of the common peroneal nerve, (3) concurrent osteofascial compartment syndrome, (4) pathological fractures, (5) poor adherence to rehabilitation/follow up, and (6) a pre-existing history of knee osteoarthritis. Table 1 reports the demographic details and patient characteristics of the study population.

\section{Surgical Techniques}

Associated with distal femoral fracture (Group A). Of nine patients, the distal femoral fracture type was $33 \mathrm{~A} 2$ in two patients, 33A3 in four patients, 33B2 in two patients, and 33B3 in one patient (according to the AO/OTA Fracture and Dislocation Classification).

For patients with 33A2 AND 33A3fractures, we used a standard open lateral approach to the distal femur. The incision was extended slightly distally to expose the avulsion fracture of the tibial insertion of the ALL. First, the distal femoral fracture was repaired utilizing minimally invasive plate osteosynthesis (MIPO) techniques. The ALL tibial avulsion fracture bed was cleared of intervening soft tissue under direct visualization, and dissection continued proximally until the origin of the ALL was identified. After identification of the ALL, the avulsion fracture block was accurately reduced and fixed (Figure 1). For patients with type 33B2 and 33B3 fractures, a medial incision was performed to reduce and fix the fracture of the medial femoral condyle, then a lateral incision was made to fix the ALL tibial avulsion 
fracture. The lateral incision was made at the midpoint between Gerdy's tubercle and the apex of fibular head.

Associated with tibial plateau fracture (Group B). Of the 10 patients with tibial plateau fracture, six patients also had an anterior cruciate ligament ( $\mathrm{ACL}$ ) avulsion fracture. After management of the tibial plateau fracture was performed, the ACL avulsion fracture was fixed with steel wire or nonabsorbable sutures passed through the ACL insertion in a figure-of-eight and brought through a tibial tunnel. After adequate reduction and fixation of the tibial plateau and ACL avulsion fractures as confirmed by the image intensifier, the ALL tibial avulsion fracture was fixed.

Associated with the tibial intercondylar eminence avulsion fracture (Group C). Of the four patients, the ACL avulsion fracture was fixed first with nonabsorbable sutures passed in a figure-of-eight through the ACL insertion and brought through a tibial tunnel under arthroscopic assistance and anchored distally in the tibia, followed by reduction and fixation of the ALL tibial avulsion fracture via a small lateral incision.

\section{Clinical Assessment}

After the associated fracture had been fixed, the pivot-shift test was performed by the senior attending surgeon prior to fixing the ALL tibial avulsion fracture $[27,28,48,43]$. The patients were routinely followed up at $1,3,6,12$, and 24 months postoperatively. They were usually discharged from orthopaedic care at 24 months of follow-up. During the follow-up appointments, $X$-ray images were obtained, and the the fracture healing was determined based on clinical exam and imaging. The postoperative pivot-shift test, International Knee Documentation Committee (IKDC) score [27, 43], Lysholm score, and Tegner activity level [43] were recorded at 2 year follow up.

\section{Statistical Analysis}

Statistical analysis was performed using the software package SPSS (Version 120.0, IBM Corp). Descriptive statistics including means and standard deviations were obtained from continuous data. Data are presented as mean values with ranges. Chi-square analysis was used for categorical variables, and the Mann-Whitney $U$ test was used to compare parametric or nonparametric variables. The KruskalWallis $\mathrm{H}$ test was used to compare was used to compare the postoperative objective IKDC evaluation. Statistical significance was defined at $P<.05$.

\section{Results}

\section{Demographics}

The mean postoperative follow-up was $31.48 \pm 6.9$ months. All fractures treated were well healed by an average time of $11.13 \pm 1.0$ weeks. The ALL was confirmed and visualized in all 23 patients. During the operation, we confirmed that the femoral origin of the ALL was located on the lateral condyle. The position was slightly anterior to the attachment point of the lateral collateral ligament and inserted at the lateral meniscus body and lateral condyle of the tibia. The tibial insertion was more specifically located 
on the lateral edge of the tibial plateau, at the midpoint between Gerdy's tubercle and the fibular head (Figure 1).

\section{Range of Motion}

At the last follow-up, the motion of the knee joint was considered to be full motion in all subgroups. The mean extension and flexion were $0.87 \pm 1.96$ and $130.2 \pm 9.9$, respectively (Table 2 ). There were no differences in extension and flexion among the three subgroups $(P>0.05)$.

\section{Subjective Knee Evaluation}

At the last follow-up, the mean subjective IKDC score of three groups (group A, group B, and group C) were $83.9 \pm 10.4,81.3 \pm 10.6$, and $81.3 \pm 10.6$, respectively. The mean Lysholm score of the three groups (group A, group B, and group C) were $85.3 \pm 13.6,82.9 \pm 11.9$, and $91.5 \pm 10.0$, respectively. The mean Tegner score of the three groups (group A, group B, and group C) were $7.4 \pm 1.3,7.2 \pm 1.2$, and $8.3 \pm 1.0$, respectively (Table 2). No statistically significant difference was found among the three groups for the subjective IKDC score, Lysholm score, and Tegner score at 2-year follow-up $(P>0.05)$.

\section{Objective Evaluation}

At the last follow-up, IKDC objective score was grade A in 14 patients, grade B in 6 patients, and 3 were graded C. Subgroup results of IKDC subjective scores are presented in Table 3. There were no significant differences among the three groups. Prior to fixation of the Segond fracture, 19 (82.6\%) patients had grade 1 , and $4(17.4 \%)$ patients had grade 2 pivot-shift test results. Postoperatively, $20(87.0 \%)$ patients had a negative pivot shift (grade 0$), 2(8.7 \%)$ patients had grade 1 , and $1(4.3 \%)$ patient had a grade $2(P<$ .0001) (Table 3).

\section{Imaging findings}

At the last follow-up, the anteroposterior and lateral X-ray images of the knee joints showed that all the fractures were well healed. There was no secondary loss of reduction, and hardware remained in place and intact (Figure2, Figure 3).

\section{Discussion}

In this study, we confirmed the existence of the ALL as a distinct ligamentous structure in the anterolateral portion of the knee in all patients and provided evidence that fixation of the ALL tibial avulsion fracture was effective in reducing rotational laxity assessed by the pivot-shift test acutely and at 2-year follow-up.

Since 2013, many authors have studied the ALL's anatomy in cadaveric dissections. However, the results of these articles have produced some contradictions. Some authors reported the universal existence of the ALL, whereas other authors stated it was present in only some of their specimens or were unable to 
find it in any of their specimens. In the current study, the ALL was found and confirmed in all 23 patients. The Segond avulsion fractures were located at the external margin of the tibial plateau, at the midpoint between Gerdy's tubercle and the fibular head (i.e., the ALL tibial insertion). Careful dissection along the insertion to the proximal aspect of the ALL showed that the femoral origin was located on the lateral condyle slightly anterior to the attachment point of the lateral collateral ligament. To our knowledge, this study is the first to describe the existence of the ALL in periarticular knee fractures in combination with fixating the Segond avulsion fracture. Several previous studies investigated the relation of the Segond fracture with the ALL using cadaveric knees [6] or using MRI in normal knees [35, 41]. However, conflicting evidence was found between MRI studies. Although Porrino et al. [35] reported that the structure is identifiable on MRI and appears to be attached to the Segond fracture fragment, they suggested forgoing an attempt to separate this lateral structure into multiple components because these structures are not reliably discriminated on routine MRI. Perhaps this helps to explain the results of Shaikh [41]. There were also broad variations in identification of the ALL using MRI between cadaveric studies and clinical studies. Both cadaveric studies reported that the ALL was clearly observed in all dissected knees and MRI scans $(100 \%)[7,20]$. In clinical studies, Taneja et al. [46] reported that the ALL was completely visible in $11 \%$ and partially visible in $40 \%$. Coquart et al. [11] reported completely visible in $82 \%$ and partially visible in $11.5 \%$. Helito et al. [18] reported completely visible in $33.3 \%$ and partially visible in $48.5 \%$. A recent study reported that the percentage agreement between MRI and surgical findings was $88 \%$ for ALL injury. One of the reasons for this variation was the different conditions for MRI visualization. Standard slice thickness of $3 \mathrm{~mm}$ was used in clinical studies, while more thin slices (0.4 and 0.6-1.5 mm) were used in cadaveric studies. Exactly what constitutes the best conditions for MRI visualization of the ALL are still under study [1]. Patel et al. [34] described a technique for identification of the ALL. A 1.5 T, or preferably 3.0T MRI should be used, with slice thickness set to $0.5 \mathrm{~mm}$ to $1.0 \mathrm{~mm}$ using a dedicated knee coil. The knee should be in flexion of $15^{\circ}$ with neutral rotation. The gold standard of ALL confirmation is surgical exploration and histological analysis in normal knees. Our study identified the ALL in $100 \%$ of the patients with Segond fracture with direct visualization during surgical exploration. A recent study evaluated the ALL histological structure in 25 knees during total knee arthroplasty. The histological analysis of the three components sampled (capsule, ACL and ALL) showed significant differences between capsule and ALL, and similarities were found comparing the ALL with ACL [38].

Parsons et al. [33] investigated the biomechanical significance of the ALL with internal rotation and anterior drawer testing from between $0^{\circ}$ and $90^{\circ}$ of knee flexion. They confirmed the ALL is an important stabilizer of the knee during internal rotation at flexion angles greater than $35^{\circ}$, and the lateral collateral ligament was not a primary stabilizer of either anterior drawer or internal rotation at any angle of knee flexion. Rasmussen et al. [37] explored the function of the ALL using 10 fresh-frozen human cadaver knees in a simulated pivot-shift test. The authors confirmed that the ALL provides rotatory stability to the knee. Specifically, the ALL was a significant secondary stabilizer during an applied internal rotation torque and simulated pivot-shift test in the context of an ACL-deficient knee. Nitri et al. [31] reported that in the face of a combined ACL and ALL deficiency, concurrent ALL reconstruction (ALLR) and ACL reconstruction (ACLR) significantly reduced internal rotation and laxity during a simulated pivot-shift test 
compared with isolated ACLR. It is well documented that a certain group of patients after ACL reconstruction (ACLR) still have persistent rotatory laxity and pivot shift [9]. Ferretti et al. [15] reported that the incidence of ALL injuries associated with ACL tears is about $90 \%$. For these reasons, several clinical studies of combined ACLR and ALLR have been performed and have reported improved rotatory stability of the knee $[27,29,42,43,48]$. Studies have shown that the pivot-shift test is a reliable examination in evaluating functional instability $[4,25]$. In our study, there were 19 patients with a grade-2 pivot-shift test and 4 patients with a grade- 3 pivot-shift before operative treatment of the ALL avulsion. At follow-up, $87.0 \%$ of patients showed a negative pivot shift $(P<.001)$. Furthermore, although not clinically significant $(P>.05)$, our subgroup analysis showed that the subjective IKDC score, Tegner score, Lysholm score were better in group $\mathrm{C}$ compared with those in group $\mathrm{A}$ and $\mathrm{B}$ at the follow-up. A difference between these groups may be indicative of an effect of a tibial plateau fracture and distal femur fracture on knee joint stability. Our results suggest an important effect of the ALL on knee stability and may indicate that a Segond fracture associated with periarticular fractures of the knee should be repaired. However, Melugin et al. [28] reported that patients undergoing ACLR with and without a Segond fracture had similar pivotshift test results, graft failure rates, and activity levels. Cavaignac et al. [8] proposed that the lack of difference found in the Melugin study could be due to analysis bias, selection bias, and interpretation bias. The most important point raised by Cavaignac is that the term Segond fracture should be reserved for bony avulsions seen on plain radiographs, rather than on MRI and ultrasonography. We agree with these views.

The present study has some limitations. First, this study was a retrospective study without a control group. Second, there was selection bias inherent to the study population. The purpose of this study was to evaluate all patients with ALL avulsion, so different associated fractures around the knee were included. Third, a low sample size population was available for our study. Additionally, there was no equipment to evaluate pivot shift quantitatively, and the pivot-shift test and grading for evaluating rotational instability is a subjective test. Finally, a 2-year follow-up period is not long enough to evaluate for potential degenerative changes which were not assessed in our study, and longer follow-up periods are required to evaluate for that outcome.

\section{Conclusions}

This study confirmed the existence of the ALL as a distinct ligamentous structure in the anterolateral portion of the knee in all patients. The fixation for the avulsion fracture of the tibial insertion of the ALL associated with periarticular knee fractures can be an effective procedure for reducing instability and increasing objective patient outcome scores with low complication rates. Longer term and comparative follow-up studies are necessary to confirm the effects.

\section{Abbreviatons}


Anterolateral ligament

IKDC

International Knee Documentation Committee

MIPO

Minimally invasive plate osteosynthesis

ACL

Anterior cruciate ligament

\section{Declarations}

\section{Acknowledgements}

No

\section{Ethical review committee statement}

This retrospective case series study was performed after obtaining approval from the ethics committee of the institutional research board (number 2019-112).

\section{Funding}

The work is supported by the Young Scientists Fund of the National Science Foundation of China (81101358)

\section{Author information}

\section{Affiliations}

Department of Orthopaedic Trauma, Tianjin Hospital, Tianjin 300211, China

Xuelei Wei, Yandong Lu, Jie Sun

Department of Sports Medicine, Tianjin Hospital, Tianjin 300211, China

Zengliang Wang

Director of Orthopaedic Trauma, Pikeville Medical Center, Pikeville, KY, USA.

John Riehl

Contributions 
Xuelei Wei (MD) and Zengliang Wang (MD) contribute equally to this work. Jie Sun (MD), Xuelei Wei, and Zengliang Wang conceived the study, carried out the tests, analysed data, and wrote the manuscript. From June 2014 to May 2017 retrospective review of medical records by Xuelei Wei, Zengliang Wang, Yandong LU (MD), and Jie Sun. John Riehl (MD) assisted with study design, contributed with writing of the manuscript, and critically reviewed the manuscript for intellectual content. All the authors including the corresponding author and co-authors have contributed in study design, review of the study as ethical issues compliance and protocol adherence, statistical analysis, results release, discussion, conclusion and recommendations. The author(s) read andapproved the final manuscript.

\section{Corresponding author}

Correspondence to Jie Sun.

\section{Ethics declarations}

\section{Ethics approval and consent to participate}

The authors declare compliance with ethical standards.

\section{Consent for publication}

Not applicable

\section{Competing interests}

The authors declare that they have no competing interest.

\section{References}

1. Andrade R, Rebelo-Marques A, Bastos R, Zaffagnini S, Seil R, Ayeni OR, et al. Identification of Normal and Injured Anterolateral Ligaments of the Knee: A Systematic Review of Magnetic Resonance Imaging Studies. Arthroscopy. 2019;35(5):1594-613.e1.

2. Ariel de Lima D, Helito CP, Daggett M, Neto FMM, de Lima LL, Leite JAD, et al. Anterolateral ligament of the knee: a step-by-step dissection. BMC Musculoskelet Disord. 2019;20(1):142.

3. Ariel de Lima D, Helito CP, Lacerda de Lima L, de Castro Silva D, Costa Cavalcante ML, Dias Leite JA. Anatomy of the Anterolateral Ligament of the Knee: A Systematic Review. Arthroscopy. 2019;35(2):670-681.

4. Bhardwaj A, Solanki NS, Jain H, Raichandani K, Raichandani S, Daruwalla V. Comparison of outcome after ACL reconstruction in terms of subjective assessment of symptoms and function and clinical assessment of ligament stability. J Clin Orthop Trauma. 2018;9(2):172-4.

5. Claes S, Vereecke E, Maes M, Victor J, Verdonk P, Bellemans J. Anatomy of the anterolateral ligament of the knee. J Anat. 2013;223(4):321-8. 
6. Claes S, Luyckx T, Vereecke E, Bellemans J. The Segond fracture: a bony injury of the anterolateral ligament of the knee. Arthroscopy. 2014;30(11):1475-82.

7. Caterine S, Litchfield R, Johnson M, Chronik B, Getgood A. A cadaveric study of the anterolateral ligament: re-introducing the lateral capsular ligament. Knee Surg Sports Traumatol Arthrosc. 2015;23(11):3186-95.

8. Cavaignac E, Saithna A, Monaco E, Helito CP, Daggett M, Reina N, et al. Is Treatment of Segond Fracture Necessary With Combined Anterior Cruciate Ligament Reconstruction? Letter to the Editor. Am J Sports Med. 2018;46(5):NP13-4.

9. Chambat P, Guier C, Sonnery-Cottet B, Fayard JM, Thaunat M. The evolution of ACL reconstruction over the last fifty years. Int Orthop. 2013;37(2):181-6.

10. Cho HJ, Kwak DS. Anatomical Consideration of the Anterolateral Ligament of the Knee. Biomed Res Int. 2019;2019:5740473.

11. Coquart B, Le Corroller T, Laurent PE, Ollivier M, Pradel V, Champsaur P, et al. Anterolateral ligament of the knee: myth or reality? Surg Radiol Anat. 2016;38(8):955-62.

12. Daggett M, Helito C, Cullen M, Ockuly A, Busch K, Granite J, et al. The Anterolateral Ligament: An Anatomic Study on Sex-Based Differences. Orthop J Sports Med. 2017;5(2):2325967116689387.

13. Dodds AL, Halewood C, Gupte CM, Williams A, Amis AA. The anterolateral ligament: anatomy, length changes and association with the segond fracture. Bone Jt J. 2014;96(B):325-31.

14. Dombrowski ME, Costello JM, Ohashi B, Murawski CD, Rothrauff BB, Arilla FV, et al. Macroscopic anatomical, histological and magnetic resonance imaging correlation of the lateral capsule of the knee. Knee Surg Sports Traumatol Arthrosc. 2016;24(9):2854-60.

15. Ferretti A, Monaco E, Fabbri M, Maestri B, De Carli A. Prevalence and Classification of Injuries of Anterolateral Complex in Acute Anterior Cruciate Ligament Tears. Arthroscopy. 2017;33(1):147-54.

16. Helito CP, Bonadio MB, Soares TQ, da Mota e Albuquerque RF, Natalino RJ, Pécora JR, et al. The meniscal insertion of the knee anterolateral ligament. Surg Radiol Anat. 2016;38(2):223-8.

17. Helito CP, Demange MK, Bonadio MB, Tírico LE, Gobbi RG, Pécora JR, et al. Anatomy and Histology of the Knee Anterolateral Ligament. Orthop J Sports Med. 2013;1(7):2325967113513546.

18. Helito CP, Demange MK, Helito PV, Costa HP, Bonadio MB, Pecora JR, et al. Evaluation of the anterolateral ligament of the knee by means of magnetic resonance examination. Rev Bras Ortop. 2015;50(2):214-9.

19. Helito CP, do Prado Torres JA, Bonadio MB, et al. Anterolateral Ligament of the Fetal Knee: An Anatomic and Histological Study. Am J Sports Med. 2017;45(1):91-6.

20. Helito CP, Helito PV, Bonadio MB, et al. Correlation of Magnetic Resonance Imaging With Knee Anterolateral Ligament Anatomy: A Cadaveric Study. Orthop J Sports Med. 2015;3(12):2325967115621024.

21. Herbst $E$, Albers $M$, Burnham JM, et al. The anterolateral complex of the knee: a pictorial essay. Knee Surg Sports Traumatol Arthrosc. 2017;25(4):1009-14. 
22. Herbst E, Albers M, Burnham JM, Fu FH, Musahl V. The Anterolateral Complex of the Knee. Orthop J Sports Med. 2017;5(10):2325967117730805.

23. Ingham SJM, de Carvalho RT, Martins CAQ, et al. Anterolateral ligament anatomy: a comparative anatomical study. Knee Surg Sports Traumatol Arthrosc. 2017;25(4):1048-54.

24. Kittl C, El-Daou H, Athwal KK, Gupte CM, Weiler A, Williams A, et al. The role of the anterolateral structures and the ACL in controlling laxity of the intact and ACLdeficient knee. Am J Sports Med. 2016;44:345-54.

25. Kocher MS, Steadman JR, Briggs KK, Sterett WI, Hawkins RJ. Relationships between objective assessment of ligament stability and subjective assessment of symptoms and function after anterior cruciate ligament reconstruction. Am J Sports Med. 2004;32(3):629-34.

26. Kraeutler MJ, Welton KL, Chahla J, LaPrade RF, McCarty EC. Current concepts of the anterolateral ligament of the knee: anatomy, biomechanics, and reconstruction. Am J Sports Med. 2018;46(5):1235-42.

27. Lee DW, Kim JG, Cho SI, Kim DH. Clinical Outcomes of Isolated Revision Anterior Cruciate Ligament Reconstruction or in Combination With Anatomic Anterolateral Ligament Reconstruction. Am J Sports Med. 2019;47(2):324-33.

28. Melugin HP, Johnson NR, Wu IT, Levy BA, Stuart MJ, Krych AJ. Is Treatment of Segond Fracture Necessary With Combined Anterior Cruciate Ligament Reconstruction? Am J Sports Med. 2018;46(4):832-8.

29. Monaco E, Mazza D, Redler A, Drogo P, Wolf MR, Ferretti A. Anterolateral Ligament Repair Augmented With Suture Tape in Acute Anterior Cruciate Ligament Reconstruction. Arthrosc Tech. 2019;8(4):e369-73.

30. Murgier J, Devitt BM, Sevre J, Feller JA, Cavaignac E. The Origin of the Knee Anterolateral Ligament Discovery: A Translation of Segond's Original Work With Commentary. Arthroscopy. 2019;35(2):68490.

31. Nitri M, Rasmussen MT, Williams BT, Moulton SG, Cruz RS, Dornan GJ, et al. An In Vitro Robotic Assessment of the Anterolateral Ligament, Part 2: Anterolateral Ligament Reconstruction Combined With Anterior Cruciate Ligament Reconstruction. Am J Sports Med. 2016;44(3):593-601.

32. Noyes FR, Huser LE, Jurgensmeier D, Walsh J, Levy MS. Is an anterolateral ligament reconstruction required in ACL-reconstructed knees with associated injury to the anterolateral structures? Am J Sports Med. 2017;45(5):1018-27.

33. Parsons EM, Gee AO, Spiekerman C, Cavanagh PR. The biomechanical function of the anterolateral ligament of the knee. Am J Sports Med. 2015;43(3):669-74.

34. Patel KA, Chhabra A, Goodwin JA, Hartigan DE. Identification of the Anterolateral Ligament on Magnetic Resonance Imaging. Arthrosc Tech. 2017;6(1):e137-41.

35. Porrino J Jr, Maloney E, Richardson M, Mulcahy H, Ha A, Chew FS. The anterolateral ligament of the knee: MRI appearance, association with the Segond fracture, and historical perspective. AJR Am J Roentgenol. 2015;204(2):367-73. 
36. Potu BK, Salem AH, Abu-Hijleh MF. Morphology of anterolateral ligament of the knee: a cadaveric observation with clinical insight. Adv Med. 2016;2016:9182863.

37. Rasmussen MT, Nitri M, Williams BT, Moulton SG, Cruz RS, Dornan GJ, et al. An In Vitro Robotic Assessment of the Anterolateral Ligament, Part 1: Secondary Role of the Anterolateral Ligament in the Setting of an Anterior Cruciate Ligament Injury. Am J Sports Med. 2016;44(3):585-92.

38. Sabatini L, Risitano S, Atzori F, Volante M, Aprato A, Indelli PF, et al. Histological analysis of the anterolateral ligament of the knee. J Orthop. 2019;16(5):368-72.

39. Sabzevari S, Rahnemai-Azar AA, Albers M, Linde M, Smolinski P, Fu FH. Anatomic and Histological Investigation of the Anterolateral Capsular Complex in the Fetal Knee. Am J Sports Med. 2017 May;45(6):1383-7.

40. Schon JM, Moatshe G, Brady AW, Serra Cruz R, Chahla J, Dornan GJ, et al. Anatomic anterolateral ligament reconstruction of the knee leads to overconstraint at any fixation angle. Am J Sports Med. 2016;44(10):2546-56.

41. Shaikh H, Herbst E, Rahnemai-Azar AA, Bottene Villa Albers M, Naendrup JH, Musahl V, et al. The Segond Fracture Is an Avulsion of the Anterolateral Complex. Am J Sports Med. 2017;45(10):224752.

42. Smith PA, Thomas DM, PomajzI RJ, Bley JA, Pfeiffer FM, Cook JL. A Biomechanical Study of the Role of the Anterolateral Ligament and the Deep lliotibial Band for Control of a Simulated Pivot Shift With Comparison of Minimally Invasive Extra-articular Anterolateral Tendon Graft Reconstruction Versus Modified Lemaire Reconstruction After Anterior Cruciate Ligament Reconstruction. Arthroscopy. 2019;35(5):1473-83.

43. Sonnery-Cottet B, Thaunat M, Freychet B, Pupim BH, Murphy CG, Claes S. Outcome of a Combined Anterior Cruciate Ligament and Anterolateral Ligament Reconstruction Technique With a Minimum 2Year Follow-up. Am J Sports Med. 2015;43(7):1598-605.

44. Sonnery-Cottet B, Lutz C, Daggett M, Dalmay F, Freychet B, Niglis L, et al. The involvement of the anterolateral ligament in rotational control of the knee. Am J Sports Med. 2016;44(5):1209-14.

45. Spencer L, Burkhart TA, Tran MN, Rezansoff AJ, Deo S, Caterine S, et al. Biomechanical analysis of simulated clinical testing and reconstruction of the anterolateral ligament of the knee. Am J Sports Med. 2015;43:2189-97.

46. Taneja AK1, Miranda FC, Braga CA, Gill CM, Hartmann LG, Santos DC, et al. MRI features of the anterolateral ligament of the knee. Skeletal Radiol. 2015;44(3):403-10.

47. Thein R, Boorman-Padgett J, Stone K, Wickiewicz TL, Imhauser CW, Pearle AD. Biomechanical assessment of the anterolateral ligament of the knee: a secondary restraint in simulated tests of the pivot shift and of anterior stability. J Bone Joint Surg Am. 2016;98:937-43.

48. Ueki H, Katagiri H, Otabe K, Nakagawa Y, Ohara T, Shioda M, et al. Contribution of Additional Anterolateral Structure Augmentation to Controlling Pivot Shift in Anterior Cruciate Ligament Reconstruction. Am J Sports Med. 2019;47(9):2093-101. 
49. Wang Y, Li S, Xu D, Qian L, Jiang C, Fu M, et al. Strain distribution of the anterolateral ligament during internal rotation at different knee flexion angles: A biomechanical study on human cadavers. Knee. 2019;26(2):339-46.

\section{Tables}

\begin{tabular}{ll}
\hline TABLE 1 Demographics and Patient Characteristics of the Study Population ${ }^{\mathrm{a}}$ \\
\hline Age at time of surgery, y, Mean \pm SD & $40.7 \pm 9.1(23-55)$ \\
Sex & $7(30.4)$ \\
Female & $16(69.6)$ \\
Male & $9(39.1)$ \\
Injured side & $14(60.9)$ \\
Left & \\
Right & $9(39.1 \%)$ \\
Accompanied fracture of ALL avulsion & $10(43.5 \%)$ \\
Distal femur fracture & $4(17.4 \%)$ \\
Tibial plateau fracture & \\
Avulsion of tibial intercondylar eminence & \\
\hline
\end{tabular}


TABLE 2 Outcomes at the Last Follow-up ${ }^{a}$

Distal femur fracture (group Tibial plateau fracture (group $\quad$ Tibial eminence avulsion (group All

$\begin{array}{lll}\text { A) } & \text { B) }\end{array}$

No. of patients

9

10

4

23

Range of motion, deg

\begin{tabular}{|c|c|c|c|c|}
\hline Extension & $0.67 \pm 2.29$ & $1.40 \pm 1.83$ & $0.00 \pm 1.41$ & $0.87 \pm 1.96$ \\
\hline Flexion & $130.0 \pm 10.3$ & $128.1 \pm 9.4$ & $135.8 \pm 10.5$ & $130.2 \pm 9.9$ \\
\hline IKDC subjective score & $83.9 \pm 10.4$ & $81.3 \pm 10.6$ & $86.3 \pm 11.3$ & $83.2 \pm 10.3$ \\
\hline IKDC objective & $6 / 2 / 1 / 0$ & $5 / 3 / 2 / 0$ & $3 / 1 / 0 / 0$ & $14 / 6 / 3 / 0$ \\
\hline \multicolumn{5}{|l|}{$\mathrm{A} / \mathrm{B} / \mathrm{C} / \mathrm{D}, \mathrm{n}$} \\
\hline Lysholm score & $85.3 \pm 13.6$ & $82.9 \pm 11.9$ & $91.5 \pm 10.0$ & $85.4 \pm 12.2$ \\
\hline Tegner score & $7.4 \pm 1.3$ & $7.2 \pm 1.2$ & $8.3 \pm 1.0$ & $7.5 \pm 1.2$ \\
\hline
\end{tabular}

${ }^{\mathrm{a}}$ Data are presented as mean \pm SD.

\section{Figures}

\begin{tabular}{|c|c|c|}
\hline \multicolumn{3}{|c|}{ TABLE 3 Pivot-Shift Test Results ${ }^{\mathrm{a}}$} \\
\hline & Pre-Segond Repair & Postoperative \\
\hline \multicolumn{3}{|l|}{$\mathrm{P}<.0001$} \\
\hline Normal & 0 & 20 \\
\hline Grade $1+$ & 19 & 2 \\
\hline Grade $2+$ & 4 & 1 \\
\hline Grade 3+ & 0 & 0 \\
\hline${ }^{\mathrm{a}}$ Data & own as number of $\mathrm{p}$ & ients. \\
\hline
\end{tabular}



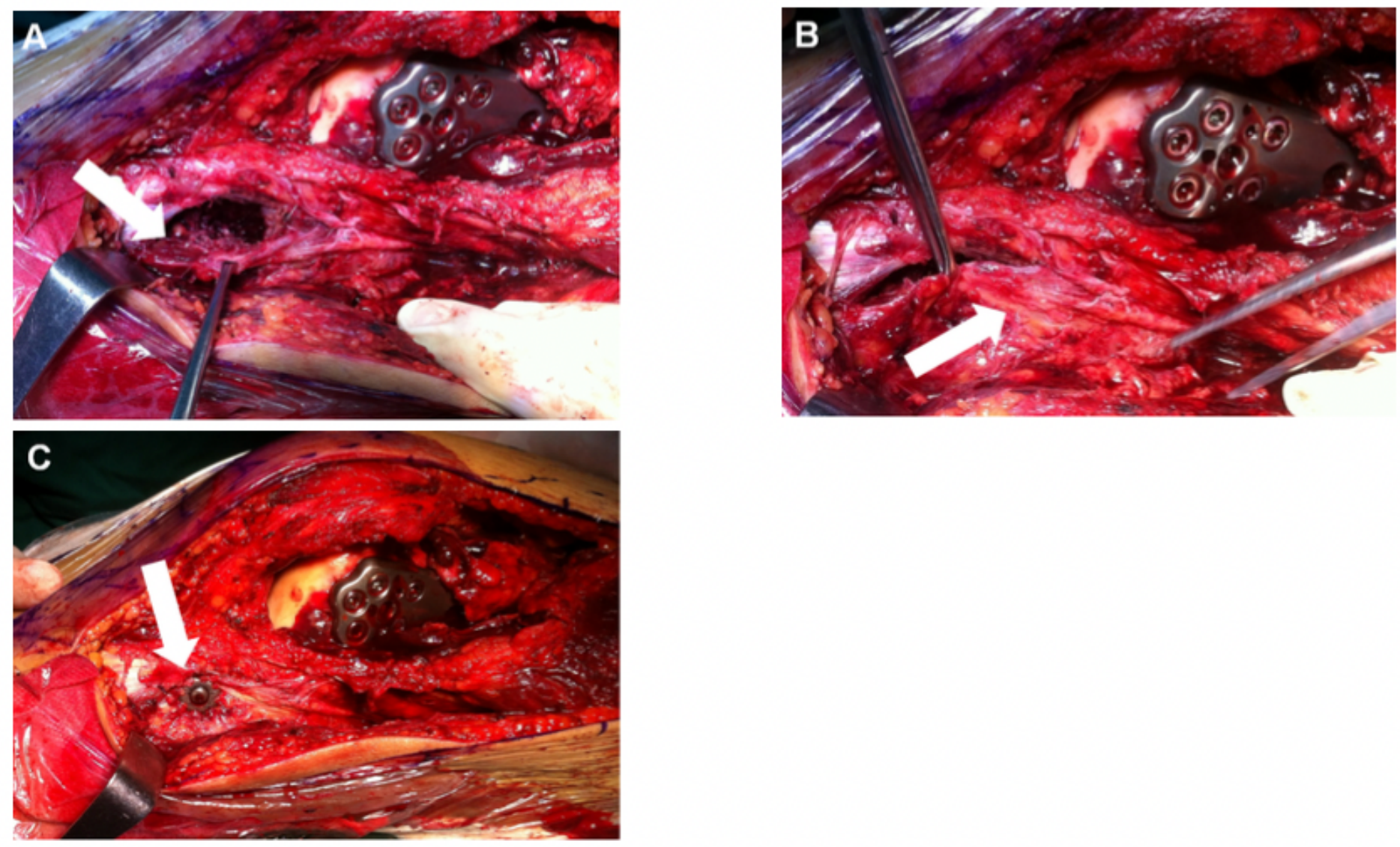

\section{Figure 1}

The ALL was identified intraoperatively. (A) the Segond avulsion fracture (arrow); (B) anterolateral ligament and its location (arrow); (C) ALL insertion avulsion fracture repaired with a spider plate 

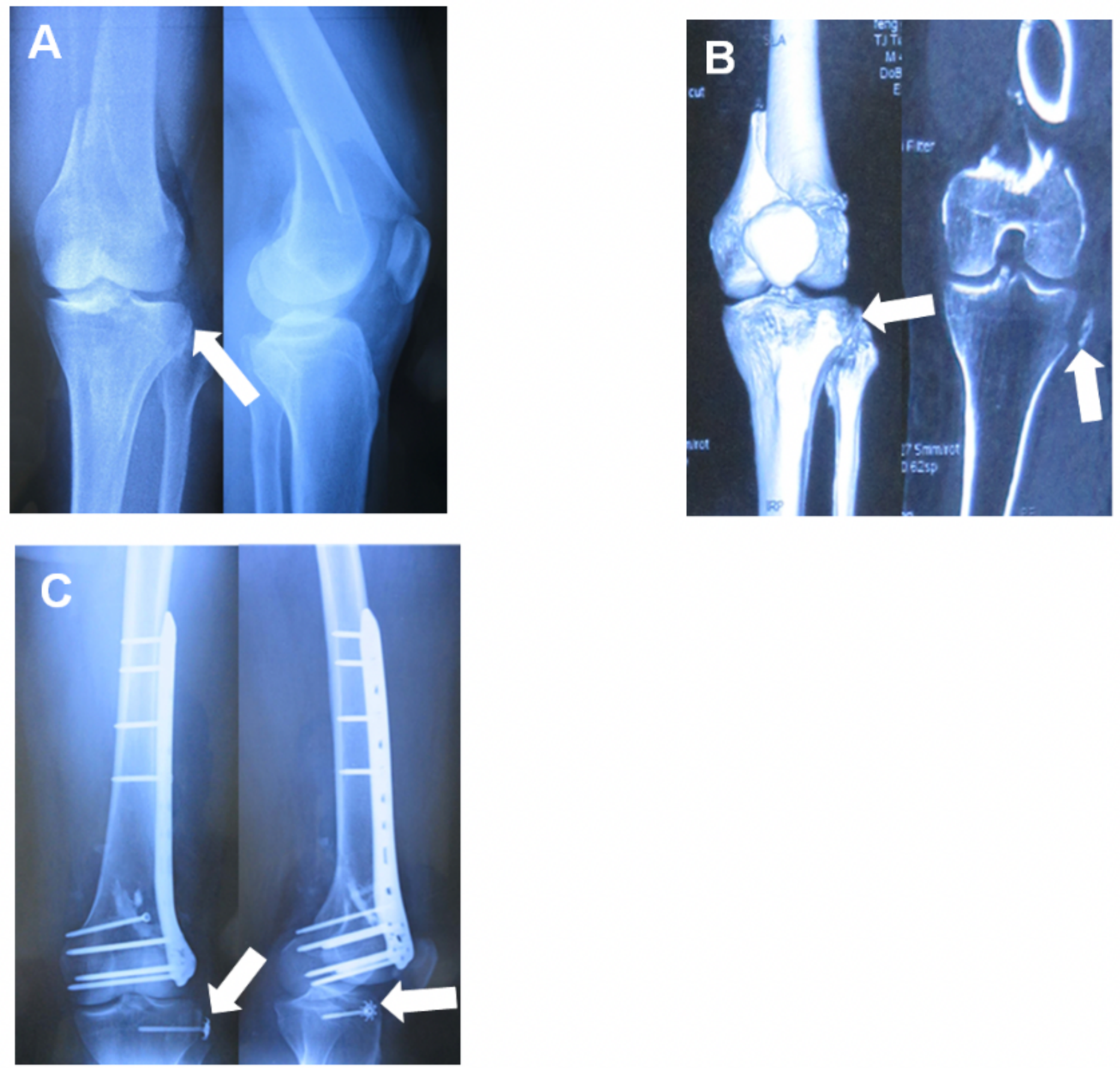

Figure 2

Male (48 year old) with blunt injury to the knee. (A) Preoperative $X$ - ray showed a distal femoral fracture with ALL tibial avulsion fracture (arrow). (B) Preoperative CT showed distal femoral fracture and ALL tibial avulsion fracture fragment (arrow). (C) Postoperative radiographs demonstrating satisfactory reduction of the distal femoral fracture and the ALL tibial avulsion fracture (arrow). 

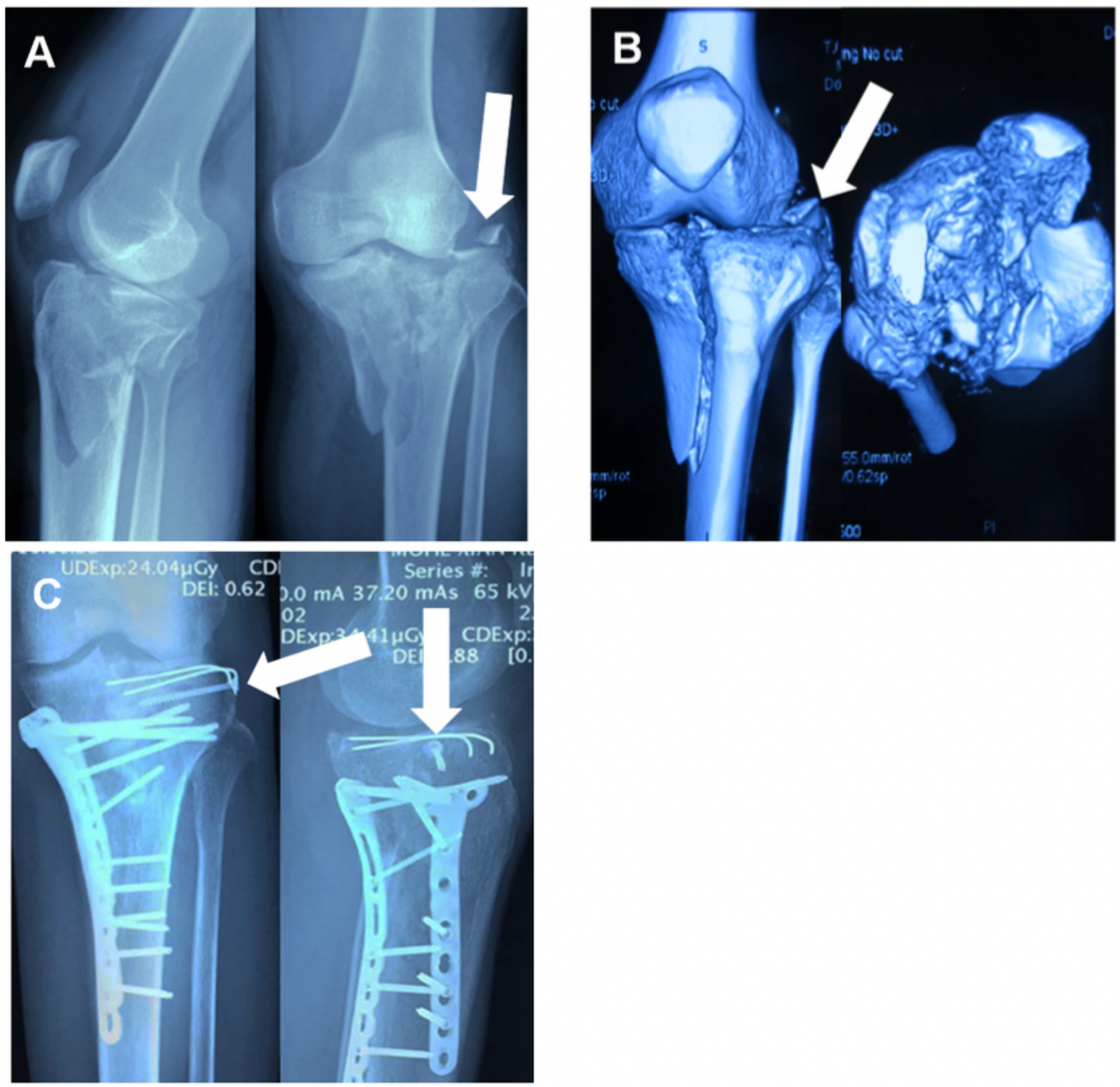

Figure 3

Male (41 year old) with injury mechanism of fall from height. (A) Preoperative $X$ - ray showed a tibial plateau fracture with an ALL tibial avulsion fracture (arrow). (B) Preoperative CT once again showed the ALL tibial avulsion fracture (arrow). (C) Postoperative radiographs after reduction and fixation of the ALL tibial avulsion (arrow) and medial plating of the tibial plateau fracture. 